\title{
PROPOSTA DE MODELO DE DESENVOLVIMENTO DE PRODUTOS FOCADA NA METODOLOGIA DE CERTIFICAÇÃO CE
}

\section{PROPOSAL FOR PRODUCT DEVELOPMENT MODEL FOCUSED ON CE CERTIFICATION METHODOLOGY}

\author{
Nathália Marcia Goulart Pinheiro* E-mail: nath.mgp@gmail.com \\ Adriana de Paula Lacerda Santos* Email: adrianapls@ufpr.br \\ Marcelo Gechele Cleto*E-mail: mgcleto@ufpr.br \\ *Universidade Federal do Paraná (UFPR), Curitiba, PR
}

\begin{abstract}
Resumo: Este trabalho apresenta uma análise crítica que compara 21 modelos de desenvolvimento de produto a fim de identificar se estas estruturas atendem às demandas da Certificação de Produtos da Comunidade Europeia (CE). Depois é apresentado um modelo de desenvolvimento de produtos, contemplando as etapas descritas nos modelos analisados acrescidas de melhorias para inclusão de atividades para certificação de produtos em relação à Conformidade Europeia, marcação CE. A melhoria proposta é justificada pela crescente busca na internacionalização de produtos e processos dentro das empresas.
\end{abstract}

Palavras-chave: Modelos de Desenvolvimento de Produto. Marcação CE.

Abstract: This paper presents a critical analysis comparing 21 product development models in order to identify whether these structures meet the demands Product Certification of the European Community (CE). Furthermore, it presents a product development model, comprising the steps in the models analyzed, including improvements in activities for referred product certification. The proposed improvements are justified by the growing quest for the internationalization of products and processes within companies.

Keywords: Product Development Models. CE Marking.

\section{INTRODUÇÃO}

As empresas que antes produziam visando o mercado nacional, atualmente enfrentam os efeitos da globalização e presenciam a queda de barreiras geográficas, tornando-se cada vez mais expostas ao mundo externo. A globalização promove expansão não só de produtos, mas também de processos, serviços e informações, além da internacionalização das empresas através de investimento direto ou indireto.

Segundo Lacerda (2004), o processo de internacionalização de empresas brasileiras é determinante para o sucesso sob os efeitos da globalização. Para manterem-se competitivas elas precisam, não só liderar o mercado local, mas 
também buscar novos mercados, fora do país de origem, agregando melhorias e tecnologias.

As teorias de internacionalização abordam algumas formas de expansão graduais ou diretas. Quando a empresa opta por expansão através da exportação, é importante considerar os requisitos aos quais seus produtos deverão atender no país de destino, que podem ser normas vigentes no país ou fatores políticos, econômicos, culturais e sociais.

Empresas que visam expandir para o mercado europeu devem adequar seus produtos às normativas vigentes e certificá-los em relação à Conformidade Europeia (CE). O procedimento de certificação dos produtos em conformidade com os requisitos da União Europeia torna-se um diferencial para as empresas, uma vez que são indicativos de qualidade.

Este trabalho sugere que o processo de certificação segundo normativas específicas deve participar do modelo de desenvolvimento de produtos desde suas etapas iniciais, pois produtos concebidos em conformidade com os requisitos estabelecidos pelas normativas têm maior chance de obterem a certificação, uma vez que foram projetados para atender tais requisitos.

Neste contexto, este artigo, além de uma revisão bibliográfica sobre 21 modelos de desenvolvimento de produtos, propõe um modelo com melhorias focadas na inserção de atividades visando a certificação do produto em relação à Conformidade Europeia, desde sua concepção até a fase de lançamento, nas devidas etapas de desenvolvimento.

\section{CERTIFICAÇÃO DE PRODUTOS SEGUNDO A CONFORMIDADE EUROPEIA (CE)}

Segundo a Europa Commission, a certificação Conformidade Europeia confere a marcação CE, que indica que o produto no qual ela está afixada está em conformidade com as exigências estabelecidas pelas diretivas da União Europeia. Essas diretivas se aplicam a todos os produtos fabricados para utilização dentro da Associação Europeia de Livre Comércio (AELC), substituindo as normas de segurança individuais de cada país. Tanto os equipamentos produzidos na União 
Europeia quanto os equipamentos exportados para União Europeia devem estar em conformidade com as exigências de segurança.

A União Europeia desenvolveu um sistema de harmonização das exigências de saúde e segurança dos produtos, inscritas em diretivas de política global. O mesmo produto pode estar sujeito a uma ou mais diretivas. No caso de produtos sujeitos a mais de uma diretiva, este só poderá apresentar a marcação CE se estiver em conformidade com todas as diretivas que se aplicam a ele.

Para um produto que está de acordo com as exigências de todas as diretivas aplicáveis a ele, o fabricante ou importador redige e assina uma declaração de conformidade da União Europeia. Em seguida, a marcação CE deve ser colocada no produto e/ou embalagem. A declaração de conformidade é de responsabilidade do fabricante e deve estar disponível para fiscalização por até dez anos após o produto ter sido comercializado pela última vez.

Os principais produtos abrangidos pelas diretivas da União Europeia que determinam a regulamentação de saúde e segurança são: equipamentos de pressão, incluindo encanamentos; todos os tipos de maquinário; equipamentos elétricos e eletrônicos; equipamentos e instrumentos médicos; equipamentos de proteção pessoal; equipamentos usados em ambientes potencialmente explosivos.

Uma vez que as diretivas abrangem quase todos os tipos de produtos que podem representar perigo à saúde e segurança da população, elas substituem as normas dos países individuais. A conformidade com as diretivas que se aplicam ao produto garante a segurança e saúde de produtores e usuários, possibilitando a livre comercialização entre os países da União Europeia.

A marcação CE indica aos consumidores que o produto cumpre os mínimos padrões de saúde segurança, o que representa sua qualidade, portanto, um produto que tenha a marcação CE pode ser livremente comercializado na União Europeia e na Área de Livre Comércio da Europa.

Para obter a declaração de conformidade do produto com as diretivas da União Europeia e consequentemente a marcação CE, deve-se realizar as seis etapas descritaa seguir (EUROPA COMMISSION, 2014):

a) Fazer um estudo sobre o produto para determinar quais diretivas da União Europeia aplicam-se a ele: Para dar início ao processo de certificação CE deve-se identificar quais diretivas podem ser aplicadas ao produto, 
através do site oficial da Comunidade Europeia, que fornece uma lista de ramos industriais e/ou empresariais que podem ser certificados através das diretivas da União Europeia. Entre esses ramos, encontram-se a indústria aeroespacial, indústria automotiva, biotecnologia, química, construção civil, indústria de defesa, indústria elétrica e eletrônica, indústria alimentícia, indústria de calçados, indústria moveleira, saúde, tecnologias de informação, indústria de couro, metrologia, indústria de embalagens, indústria marítima, equipamentos mecânicos, mineração, equipamentos de gás e pressão, equipamentos de rádio e telecomunicação, indústria têxtil, turismo, indústria de brinquedos e indústria de madeira, papel e impressão. A Comunidade Europeia fornece suporte também aos setores governamental, gerencial, sustentabilidade e responsabilidade ambiental, engenharias elétrica e mecânica, direção de informática, inovação da tecnologia de informação, competitividade, eficiência energética, comércio internacional, desenvolvimento tecnológico, entre outros. Além das diretivas aplicáveis diretamente ao setor em que se enquadra o produto, quando se trata de produtos a serem exportados para a União Europeia, a empresa pode se beneficiar das políticas de atividades internacionais, que objetivam orientar as indústrias a enfrentar os desafios da globalização. A União Europeia analisa a política industrial de outros países e blocos comerciais, avaliando o impacto econômico sobre os diversos setores. O objetivo das diretivas relacionadas a esses requisitos é assegurar que as políticas comerciais das empresas as tornam competitivas, estimulando o crescimento econômico e a criação de empregos. Além disso, procura-se assegurar uma representação adequada dos interesses da União Europeia, utilizando uma série de atividades que facilitam o comércio europeu.

b) Levantar as normas harmonizadas a serem cumpridas para assegurar a conformidade do produto com as regras de segurança e saúde a que se aplicam: As normas harmonizadas constituem-se de um conjunto de regras para garantir a segurança dos produtos em vários aspectos. Para cada produto se aplicam um conjunto de normas específicas ao tipo de utilização, produção e manutenção. A partir da relação de normas apresentada pela 
União Europeia deve ser definido um conjunto constituído de todas as normas aplicáveis ao produto dentro do setor em que se enquadra.

c) Determinar a quais ensaios o produto deverá ser submetido, a partir dos ensaios apresentados pelas normas harmonizadas selecionadas: Baseado nas normas selecionadas que se aplicam ao produto, deve-se elaborar um Plano de Ensaio que irá conduzir os ensaios para verificação da conformidade em relação aos requisitos estabelecidos em cada uma das normas apresentadas na etapa anterior. O Plano de Ensaio define quais são os ensaios que deverão ser realizados para verificar a compatibilidade do produto com os requisitos, além dos limites aceitáveis em cada um dos ensaios para que o produto seja considerado aprovado. Existem alguns critérios de avaliação do desempenho do produto que são também determinados pelas normas e devem constar no Plano de Ensaio. Todas as informações que podem ser úteis para a realização do ensaio, como por exemplo, a identificação do produto a ser testado, os equipamentos, ferramentas e instrumentos auxiliares utilizados no ensaio, a configuração do ensaio e as condições ambientais de referência, devem constar no Plano de Ensaio, a fim de facilitar a sua realização. A utilização de um plano de ensaio é importante, pois garante clareza e objetividade na realização dos ensaios o que se reflete em resultados confiáveis.

d) Avaliar se o produto atende todas as exigências das diretivas aplicáveis: Uma vez criado o Plano de Ensaio, deve-se procurar os laboratórios qualificados para realização dos ensaios de tipo no produto. Os ensaios podem ser realizados no laboratório da própria empresa, desde que possua os instrumentos necessários pra medição de todos os parâmetros que indicam a conformidade do produto com os limites estabelecidos nas normas harmonizadas. O fabricante é responsável pela veracidade e confiabilidade dos resultados apresentados pelos ensaios e também pela fabricação de produtos com a qualidade compatível com a da unidade submetida aos ensaios. A partir dos resultados dos ensaios realizados, deve ser criado um Relatório de Ensaios de Tipo, que contém a descrição dos ensaios realizados, os instrumentos utilizados conforme o plano de ensaio e os resultados obtidos. Se os ensaios forem realizados em um laboratório externo à 
empresa, é recomendado anexar os resultados fornecidos pelo laboratório no Relatório de Ensaios de Tipo.

e) Preparar a Documentação Técnica que regulamenta a conformidade do produto com as diretivas atuais da União Europeia: Neste momento, a parte de avaliação do produto já está completa e é necessário levantar toda a documentação técnica que comprova os resultados obtidos na avaliação. A documentação técnica deve conter: uma descrição geral das características técnicas e funcionalidades do produto, sendo comum que estas características estejam no seu manual técnico; desenhos de projeto e fabricação, esquema de componentes, montagem e sub montagens, esquemáticos, circuitos, entre outros documentos que contenham descrições e explicações úteis para fabricação do produto; uma lista das normas aplicadas na verificação da conformidade com os requisitos da União Europeia e uma descrição da solução adotada para cumprir todos os requisitos especificados nas normas, conforme detalhado no Plano de Ensaio; o Relatório de Ensaios de Tipo, que apresenta os resultados e a desempenho obtido pelo produto, comprovando que o mesmo está em conformidade com os requisitos estabelecidos pela União Europeia de forma clara, precisa e confiável; os manuais de instrução, operação, instalação e manutenção do produto, destinados aos usuários, que devem ser coerentes com sua funcionalidade e conter todas as informações úteis para sua utilização segura em todas as configurações e condições previstas e asseguradas pelos ensaios de tipo. A documentação técnica deve estar disponível na comunidade Europeia por pelo menos dez anos após a última fabricação do produto. Se o fabricante não for da comunidade Europeia, o representante que comercializa o produto é responsável pela documentação.

f) Redigir e emitir a Declaração de Conformidade, conferindo a Marcação CE ao produto: Uma vez que o produto já foi avaliado e aprovado, e apresenta sua documentação técnica completa, deve-se redigir a Declaração de Conformidade que certifica sua marcação CE. Algumas informações são obrigatórias na Declaração de Conformidade, tais como uma referência direta à diretiva que foi aplicada na avaliação do produto; a identificação correta do produto, conforme determinado nesta diretiva; o nome e endereço do 
fabricante na União Europeia e, quando o fabricante não for instalado na União Europeia, a indicação de seu representante local que ficará responsável pela declaração e pela conformidade do equipamento com os requisitos determinados na diretiva; uma referência datada às especificações ao abrigo das quais a conformidade é declarada, para verificar a conformidade com a diretiva; a data de emissão da Declaração de Conformidade; a identificação e assinatura do responsável pela fabricação do produto e/ou seu representante na União Europeia. Além da Declaração de Conformidade o fabricante deverá afixar em todos os produtos cuja conformidade com os requisitos da União Europeia foi verificada, a marcação CE de qualidade. Essa marcação deverá ser produzida conforme estabelecido pelas diretivas, e deverá aparecer no produto, na embalagem e na documentação que o acompanha, como manuais de usuário e técnico. Para o caso de equipamentos enquadrados em mais de uma diretiva, a Declaração de Conformidade deverá referenciar todas as diretivas utilizadas na avaliação.

Tanto a Declaração de Conformidade como a marcação CE são de inteira responsabilidade do fabricante e devem estar disponíveis para fiscalização por órgãos representantes da União Europeia por até dez anos após a última fabricação do produto.

Em caso de produtos perigosos, é requerida a intervenção de um Organismo Notificado para realizar a avaliação da documentação técnica redigida pelo fabricante. Em alguns casos será realizada inspeção e teste físico do produto. Apenas se o Organismo Notificado aprovar a documentação técnica e o teste físico do produto, será emitida a declaração de conformidade.

A Figura 1 apresenta um modelo resumindo as seis etapas necessárias para garantir a conformidade do produto com os requisitos estabelecidos pela União Europeia, viabilizando a conferência da marcação CE. 
Figura 1 - Etapas para certificação CE dos produtos

\begin{tabular}{|c|c|c|c|c|c|}
\hline 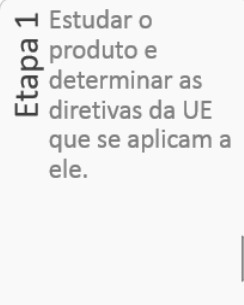 & 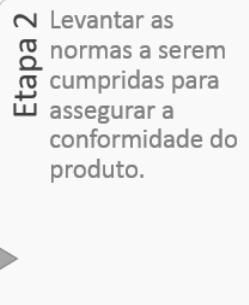 & 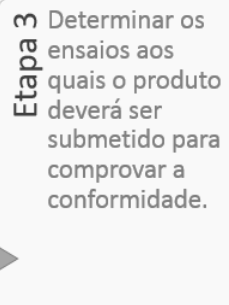 & 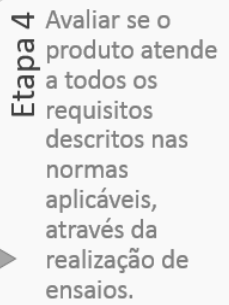 & 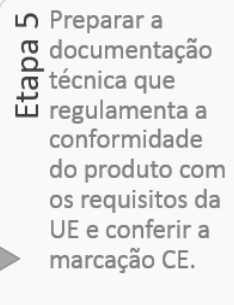 & 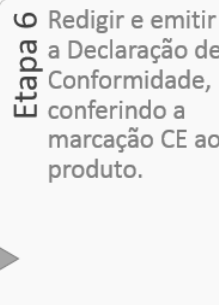 \\
\hline
\end{tabular}

Fonte: Os autores

\section{ANÁLISE COMPARATIVA DOS MODELOS DE DESENVOLVIMENTO DE PRODUTOS}

O processo de desenvolvimento de produtos envolve planejamento e um modelo que, através de etapas interativas ou não, transforma necessidades de mercado somadas à disponibilidade de recursos em produtos vendáveis e economicamente viáveis.

Segundo Silva (2011) o projeto de desenvolvimento de produtos é uma sintetização de informações em etapas ou fases com objetivos definidos, e esta informação pode fluir entre as etapas melhorando-as ainda que de forma retroativa. Dessa forma, é necessário que o desdobramento do projeto de desenvolvimento de produtos seja "em fases que garantam que os principais vínculos entre os objetivos, planejamento, implementação e verificação sejam mantidos" (SILVA, 2011).

Foram selecionados para estudo 21 modelos de desenvolvimento de produtos de autores de destaque na literatura sobre o assunto. Os pontos fortes de cada modelo estudado são descritos a seguir, seguindo a ordem cronológica da edição literária.

Asimow (1968) criou a primeira metodologia de desenvolvimento de produto conhecida. $\mathrm{O}$ autor definiu uma interação entre o projeto e o meio ambiente, fazendo uma análise da influência sócio ecológica no projeto de engenharia. Definiu ainda um ciclo de produção e consumo, onde a produção gera bens, que são distribuídos para uso dos consumidores, e quando se tornam improdutivos, são descartados. Parte do descarte é recuperada e se transforma em recursos para produção, fechando o ciclo. Seu modelo possui as seguintes etapas: identificação da necessidade; estudo da forma de execução; projeto preliminar; projeto detalhado; 
planejamento da produção; planejamento da distribuição; planejamento do consumo; planejamento da retirada do produto do mercado.

Segundo o autor, o projeto se inicia com a fase de estudo da forma de execução, onde são geradas alternativas de solução para as necessidades identificadas. Ainda nesta etapa são identificados limitações e critérios a partir dos quais as alternativas estabelecidas são classificadas de acordo com sua realização física, compensação econômica e viabilidade financeira. O projeto preliminar estabelece, dentre as alternativas sugeridas na etapa anterior, qual delas apresenta as características mais viáveis para o projeto, além de realizar estudos relativos aos materiais e às influências externas e internas no sistema. O projeto detalhado fornece descrições de engenharia para a concepção da alternativa escolhida no projeto preliminar e constrói modelos e protótipos para experimentar as ideias. $\mathrm{O}$ planejamento do processo de produção estabelece os requisitos necessários para a fabricação do produto, guardando um compromisso econômico considerável. São realizados planejamento detalhado do processo de fabricação, projeto de ferramentas e gabaritos, planejamento de instalações, sistema de controle de qualidade, planejamento para pessoal da produção, controle de produção, fluxo de informações e planejamento financeiro. O Planejamento da distribuição analisa os impactos da distribuição no projeto, resultando no projeto da embalagem, sistema de armazenagem, planejamento de atividades de promoção e cuidados com o produto para viabilizar distribuição eficiente. O planejamento do consumo adequa os serviços para melhorar o reprojeto do produto, considerando manutenção, confiabilidade, segurança, conveniência de utilização, estética, economia de operação, determinação da vida útil adequada e obtenção de feedback para aperfeiçoamento do produto. Finalmente, no planejamento da retirada do produto do mercado, pretende-se avaliar como o valor de retirada de um produto obsoleto do mercado influencia o projeto, visando a redução da obsolescência e utilização de materiais que possam ser recuperados.

Archer (1968) propôs um modelo de desenvolvimento de produto com etapas que consideram a elaboração de um programa que estabelece uma linha de ações a serem desenvolvidas, a coleta e armazenamento de dados para o desenvolvimento do produto, identificação e análise de subproblemas e preparação das especificações de desempenho, sintetização das especificações, desenvolvimento 
que valida a proposição e, finalmente, a definição dos mecanismos de comunicação entre as partes envolvidas no desenvolvimento como um todo. O modelo proposto pelo autor buscou transformar metodologias focadas na engenharia de produção em metodologias voltadas para o desenho industrial.

Kotler (1974) considera o marketing sobre o produto no processo de desenvolvimento fundamental para seu sucesso. Seu modelo contempla aspectos voltados para aceitação do mercado, demanda e satisfação do cliente através da qualidade do produto, desde a geração de uma ideia até a repercussão do produto no mercado.

Segundo o modelo de Kotler (1974), na etapa de geração de ideia são realizadas pesquisas com clientes, cientistas, engenheiros, designers, funcionários da empresa e concorrentes para identificar novos produtos possíveis. Segundo o autor, algumas técnicas podem auxiliar o processo de geração de ideias, tais como lista de atribuições, venda casada, análise morfológica, identificação da necessidade e brainstorming. Na etapa de triagem as ideias geradas são classificadas como promissoras, periféricas ou rejeitadas, visando evitar o descarte de boas ideias ou a escolha de ideias ruins. Na etapa de desenvolvimento e teste do conceito é realizada a distinção detalhada das ideias mais atrativas, através de três itens relacionados ao produto: ideia, conceito e imagem. Também nesta etapa o conceito do produto é formulado, avaliado e testado. Na etapa de desenvolvimento de estratégia de marketing é estabelecida uma estratégia preliminar de marketing, que trata a dimensão, estrutura e comportamento do mercado, planeja o preço, a forma de distribuição e o orçamento de marketing para o primeiro ano, estabelecendo informações de longo prazo, como metas de vendas e lucros e estratégias de marketing ao longo do tempo. Na etapa de análise de mercado é verificado se 0 produto realmente satisfaz os objetivos da organização e, caso satisfaça, é encaminhado para engenharia onde será desenvolvido e avaliado quanto à sua viabilidade técnica. $\mathrm{Na}$ fase de teste no mercado verifica-se se o produto é bem aceito funcionalmente e psicologicamente e, se aceito pelo mercado, está apto a receber marca, embalagem, e programa preliminar de marketing. Finalmente o produto atinge a fase de comercialização, onde decisões referentes à sua venda devem ser tomadas da melhor forma, definindo quando, onde, para quem e como as ações de comercialização devem ser desenvolvidas. 
Jones (1976) apresentou um modelo com três macro fases: divergência, transformação e convergência. Na macro fase de divergência ocorre a obtenção da informação primária, que permite explorar as alternativas para solução de um problema podendo resultar no desenvolvimento de um novo produto. Na segunda macro fase é desenvolvido um modelo de produto, ainda que não o mais adequado para a solução do problema. Também são definidos os objetivos, as ordens e as restrições do problema, bem como são identificadas as variáveis críticas e o problema é dividido em subproblemas buscando encontrar sua raiz. Podem existir várias transformações aceitáveis e diferentes entre si. Na etapa de convergência uma única alternativa é escolhida para dar continuidade ao projeto de desenvolvimento do produto.

Pahl e Beitz (1977) dividiram o projeto em subprojetos de acordo com módulos funcionais. A metodologia proposta por eles contempla uma lista dos critérios de avaliação, atribuição de fatores de ponderação, medidas e valores numéricos para classificação destes critérios, avaliação global do projeto, comparação das alternativas para seleção da melhor delas e, finalmente, consideração de incertezas para garantir a consistência do projeto. O modelo proposto apresenta um método de evolução com base em análise de valor e uso, separando as etapas por módulos funcionais, utilizando ferramentas para avaliação de critérios por escalas.

Crawford (1983) propôs um modelo de desenvolvimento de produtos considerando as etapas de identificação e seleção das oportunidades que poderão originar um novo produto; geração do conceito de uma alternativa escolhida; avaliação da viabilidade do conceito escolhido; desenvolvimento do produto; lançamento do produto no mercado.

Back (1983) tratou o projeto como uma sequência de eventos em ordem cronológica, com objetivo de transformar recursos em bens úteis. Seu modelo é composto por oito etapas: estudo da viabilidade, projeto preliminar, projeto detalhado, revisão e teste, planejamento da produção, planejamento do mercado, planejamento para o consumo e manutenção e planejamento da obsolescência. A descrição das etapas é similar às etapas apresentadas por Asimow (1968), entretanto, Back (1983), acrescentou a etapa de testes de modelos experimentais para avaliar a viabilidade técnica do produto. A medida que o projeto vai se 
desenvolvendo, as revisões e os testes ocorrem simultaneamente, porém, devido à importância desta atividade, o modelo a contempla como uma fase independente onde modelos são construídos para verificar princípios, processos, componentes e protótipos. Essas verificações são utilizadas como base para melhorias e refinamentos no projeto, de forma interativa.

Bonsiepe (1984) definiu a metodologia de desenvolvimento de projeto como uma ferramenta bastante útil nas etapas do desenvolvimento. Propôs quatro estruturas de desenvolvimento de projetos, de acordo com o fluxo de informações entre as etapas: linear, realimentada, circular e Processo Alemão.

$\mathrm{Na}$ estrutura linear o autor considerou o estabelecimento de um programa que dará origem ao desenvolvimento de produto, coleta e posterior análise de dados que possam ser úteis ao desenvolvimento, sintetização desses dados, desenvolvimento do projeto e comunicação do desenvolvimento aos envolvidos com o projeto. $\mathrm{Na}$ estrutura realimentada o autor considerou troca de informações entre as etapas, onde informações das etapas à frente podem ser utilizadas para rever etapas anteriores, de forma interativa. Na estrutura circular o autor sugeriu uma melhoria cíclica para o projeto. Na estrutura denominada Processo Alemão o autor propôs a divisão do problema em subproblemas com soluções parciais principais e, para cada solução, é formulada uma concepção diferente, até que uma única solução seja escolhida para ser desenvolvida.

Suh (1988) propôs um modelo de desenvolvimento de produtos que contempla a identificação de uma necessidade social como ponto de partida para o projeto. Após a primeira etapa ocorrem a determinação dos requisitos funcionais, determinação dos atributos do produto, protótipo e produção do produto. O autor defende a integração cíclica das áreas de projeto, produção e marketing.

Bürdek (1994) denominou seu modelo de desenvolvimento de produtos de Modelo Prático do Processo de Design. Seu modelo é composto pelas etapas: identificação do problema, análise da situação, definição do problema, geração de alternativas, avaliação e escolha e realização. O processo é estruturado através de realimentações de informações ao longo de todo o modelo. O autor fez uso de análises de mercado, funcional e de informações, lista de fatores, métodos de resolução de problemas, entre outros, com o propósito de tornar o projeto não 
redundante devido à falta ou excesso de informações ao longo do processo de desenvolvimento.

Bomfim (1995) apresentou um modelo considerando o projetista, a empresa e a sociedade como as instituições que determinam as políticas econômicas, e o produto representando as necessidades do mercado produtor e consumidor.

Roozemburg, et al. (1996) defenderam que o modelo de desenvolvimento de produtos exige uma abordagem multidisciplinar, onde a engenharia, design industrial, ergonomia, marketing e gestão da inovação, contribuem para o desenvolvimento de produto. O modelo dos autores considera o uso de métodos de avaliação e de tomada de decisão, através de análises qualitativa e quantitativa, e estabelecimento de critérios, contemplando as etapas de análise do problema, síntese das soluções, simulação das soluções, avaliação do projeto e tomada de decisão.

Prasad (1997) criou um modelo de desenvolvimento de produtos que utiliza a engenharia simultânea como auxílio para garantia da qualidade do produto, diminuindo o ciclo de desenvolvimento do produto e, consequentemente seus os custos. As etapas do seu modelo contemplam definição da missão da empresa, definição do conceito, engenharia e análise, design do produto, prototipagem, planejamento e operacionalização de engenharia, operacionalização e controle da produção, fabricação, melhoria, suporte e entrega.

Kaminski (2000) definiu o conceito de espiral de projeto, considerando que as sete etapas do projeto são interativas. Segundo o espiral, na primeira volta são desenvolvidas todas as etapas e em sequência são realizadas outras voltas, realimentando as etapas com informações das etapas seguintes, quando necessário. Também trata a qualidade na execução do projeto, abordando elementos de controle antecipativos e corretivos garantindo que o produto esteja em conformidade com as especificações de projeto. Seu modelo de desenvolvimento de produtos possui as etapas de especificação técnica das necessidades, estudo da viabilidade, projeto básico, projeto executivo, planejamento da produção/execução, planejamento da disponibilidade do cliente, planejamento do consumo ou utilização do produto e planejamento do abandono do produto.

Lobach (2001) ressaltou o designer como um criador de ideias inovadoras capaz de identificar problemas e apresentar soluções para resolvê-los. Seu modelo 
de desenvolvimento de produtos contempla 4 fases de processo criativo: análise do problema, geração de alternativas, avaliação das alternativas, realização da solução do problema.

Ulrich e Eppinger (2004) propuseram um modelo de desenvolvimento de produtos com etapas de planejamento, desenvolvimento do conceito, sistema de design, projeto detalhado, testes e refinamento e produção. Na fase que os autores chamaram de sistema de design é definida a arquitetura do produto e sua decomposição em componentes. Esta fase também define o esquema de montagem para o sistema de produção. Como resultado, estão a forma do produto, as especificações de todos os componentes e um fluxo preliminar de produção.

Pahl et al. (2005) direcionaram os métodos de desenvolvimento de produtos para o planejamento, busca e avaliação de uma solução para um problema identificado, de forma flexível que pode ser ajustada em cada caso específico. O projeto é embasado em uma visão sistêmica e metódica que prevê a utilização de ferramentas de qualidade como QFD, FMEA e análise de mercados e cenários.

Rozenfeld (2006) propôs um modelo de desenvolvimento de produtos contemplando as etapas de pré-desenvolvimento, desenvolvimento e pósdesenvolvimento. Cada etapa é composta por fases detalhadas do processo de desenvolvimento. Seu modelo apresenta um equilíbrio entre processos de desenvolvimento, tecnologias e necessidades de mercado. Utiliza diversas ferramentas como QFD, FMEA, DFX, CAD/CAE, CAPP e PLM. O autor inclui a certificação do produto na fase de preparação sem contemplar análise de requisitos para certificação na fase de projeto informacional, mencionando apenas atendimento aos requisitos de clientes. Caso o produto não seja projetado conforme os requisitos para certificação, essa etapa poderá gerar retrabalho.

Bürdek (2010) propôs uma revisão histórica sobre o design e apresenta o contexto globalizado do desenvolvimento de produtos. No modelo de desenvolvimento de projetos ele foca o processo de identificação e análise de um problema ou necessidade como principal etapa do desenvolvimento. Seu modelo considera o conceito de geração de alternativas e escolha da melhor solução.

Baxter (2011) abordou o processo de inovação no desenvolvimento de produtos. Segundo ele a globalização e as tecnologias favorecem a redução do tempo de desenvolvimento de produtos e aumentam a competitividade. Também 
abordou o conceito de funil de decisões como uma forma de visualizar variações de riscos e incertezas no processo de tomada de decisão sobre a viabilidade de um produto e seleção de alternativas. O teste de mercado é considerado desde o início do desenvolvimento do produto, na fase de apresentação da ideia. O projeto só deve ser continuado se aprovado pelos consumidores. O autor não apresentou um modelo único de desenvolvimento de produto, e sim a estrutura de gerenciamento do projeto do produto, com as seguintes etapas: oportunidades de negócios; especificação do projeto; projeto conceitual; projeto da configuração; projeto detalhado e projeto para fabricação.

O autor também apresentou 35 ferramentas de apoio ao desenvolvimento de produtos, dentre as quais estão: aplicação de conceitos chave do estilo do produto; Brainwriting, que consiste em conservar vantagens e reduzir desvantagens; Análise paramétrica quantitativa e qualitativa; Análise morfológica de todas as combinações possíveis de um produto ou sistema; MESCRAI, que significa modifique, elimine, substitua, combine, rearranje, adapte, inverta; Análise PEST, a qual considera política, economia, sociedade e tecnologia; Análise estratégica dos concorrentes; Pesquisa das necessidades do mercado; Análise do ciclo de vida do produto; Análise das falhas, suas causas, riscos evidentes e eventuais deficiências do produto.

Silva (2012) criou um modelo de desenvolvimento de produto contemplando três macro-fases: pré-desenvolvimento, desenvolvimento e pós-desenvolvimento. Cada uma delas é composta por fases detalhadas do processo que vão desde análise de mercado para verificar disponibilidade de recursos e necessidades dos clientes até o fim do ciclo de vida do produto, quando deve ser programada sua retirada do mercado de forma que seja reutilizável no desenvolvimento de novos produtos.

No pré-desenvolvimento são realizadas atividades para geração de ideias e alternativas viáveis para geração de renda e é determinado um escopo de projeto, seus recursos e limitações, além de um cronograma de execução. No Desenvolvimento o produto é definido e são realizadas pesquisas sobre tendências, público-alvo, locais de comercialização, fornecedores e ciclo de vida do produto. É elaborado o escopo do produto, que compreende características técnicas e funcionais, seus requisitos, estrutura e construção. Também é construído um 
protótipo para sua validação funcional, são definidas suas etapas de fabricação e atividades necessárias para seu lançamento junto às estratégicas de marketing da empresa. O Pós-Desenvolvimento visa obter melhorias no produto através do seu acompanhamento no mercado. Também são tomadas medidas de descontinuação do produto e retirada do mercado considerando a logística reversa necessária para tal.

O Quadro 1 apresenta um comparativo de alguns dos modelos descritos, nos quais foram encontrados parte das recomendações das normativas da CE, enfatizando suas etapas de desenvolvimento e principais características. O objetivo da comparação é evidenciar quais são as etapas que deverão ser adaptadas para inserir a adequação do projeto ao cumprimento dos requisitos estabelecidos pelas normativas da União Europeia.

\section{METODOLOGIA}

Inicialmente foram escolhidos 21 modelos de desenvolvimento de produtos, os quais foram descritos, analisados e classificados quanto as suas etapas evolutivas.

Além da análise dos modelos, foi realizado um estudo teórico sobre a implantação da certificação CE e quais são as atividades necessárias para atribuir a marcação CE aos produtos. Esse estudo foi relacionado às etapas de desenvolvimento de produtos, apontando em quais delas alguma medida é necessária para chegar à certificação.

Finalmente, foi proposto um modelo de desenvolvimento de produtos contemplando as etapas fundamentais identificadas nos modelos analisados e incluindo também as etapas para certificação CE do produto.

\section{PROPOSTA DE MODELO DE DESENVOLVIMENTO DE PRODUTOS FOCADA DA METODOLOGIA DE CERTIFICAÇÃO CE}

Como resultado desta pesquisa foi apresentado um modelo de desenvolvimento de produtos, baseado nos modelos estudados na revisão 
bibliográfica, acrescentando em suas etapas de desenvolvimento atividades que promovem a certificação CE do produto.

A inserção destas atividades desde as etapas iniciais de desenvolvimentos é justificada pelo projeto de produtos visando o mercado europeu pois, para comercialização neste mercado, é uma certificação obrigatória em quase todas as áreas de desenvolvimento. Pretende-se adequar o projeto do produto aos requisitos estabelecidos pelas normativas europeias, visando que sejam aprovados nas avaliações que conferem a certificação CE tão logo estejam prontos para lançamento no mercado.

A Figura 2 ilustra o Modelo de Desenvolvimento de Produtos proposto, composto das etapas de desenvolvimento existentes nas literaturas analisadas e indica a inclusão das atividades para certificação do produto em relação à Conformidade Europeia, em cada etapa de desenvolvimento. 
Quadro 1 - Quadro comparativo dos principais Modelos de Desenvolvimento de Produtos analisados neste trabalho

\begin{tabular}{|c|c|c|c|c|c|}
\hline \multirow[b]{2}{*}{ Modelo } & \multicolumn{3}{|c|}{ Atividade / Etapas de desenvolvimento } & \multirow{2}{*}{$\begin{array}{l}\text { Estrutura e fluxo de } \\
\text { informação }\end{array}$} & \multirow[b]{2}{*}{ Principais características } \\
\hline & Pré-desenvolvimento & Desenvolvimento & $\begin{array}{c}\text { Pós- } \\
\text { desenvolvimento }\end{array}$ & & \\
\hline $\begin{array}{l}\text { ASIMOW } \\
(1968)\end{array}$ & Estudo de exequibilidade & $\begin{array}{l}\text { Projetos preliminar e detalhado } \\
\text { Projeto detalhado } \\
\text { Planejamento para produção, distribuição } \\
\text { e consumo }\end{array}$ & $\begin{array}{l}\text { Planejamento da } \\
\text { retirada do } \\
\text { produto do } \\
\text { mercado }\end{array}$ & $\begin{array}{l}\text { Estrutura sequencial } \\
\text { sem troca de } \\
\text { informações entre } \\
\text { etapas }\end{array}$ & $\begin{array}{l}\text { Foco em engenharia e design de } \\
\text { produto, definição de um ciclo de } \\
\text { produto que vai desde as necessidades } \\
\text { até a retirada do mercado }\end{array}$ \\
\hline $\begin{array}{l}\text { KOTLER } \\
(1974)\end{array}$ & $\begin{array}{l}\text { Geração de ideias } \\
\text { Triagem de ideias }\end{array}$ & $\begin{array}{l}\text { Desenvolvimento e teste de conceitos, } \\
\text { estratégia de marketing, análise } \\
\text { comercial, protótipo do produto }\end{array}$ & $\begin{array}{l}\text { Teste de mercado } \\
\text { Comercialização }\end{array}$ & $\begin{array}{l}\text { Utiliza informações } \\
\text { dos clientes sobre a } \\
\text { satisfação com o } \\
\text { produto desde início. }\end{array}$ & $\begin{array}{l}\text { Foco no marketing do produto e forte } \\
\text { interação com ambiente externo no } \\
\text { desenvolvimento do produto }\end{array}$ \\
\hline $\begin{array}{l}\text { BACK } \\
(1983)\end{array}$ & Estudo de viabilidade & $\begin{array}{l}\text { Projetos preliminar e detalhado } \\
\text { Revisão e testes } \\
\text { Planejamento para produção, mercado e } \\
\text { consumo }\end{array}$ & $\begin{array}{l}\text { Planejamento da } \\
\text { obsolescência }\end{array}$ & $\begin{array}{l}\text { Estrutura sequencial } \\
\text { sem troca de } \\
\text { informações entre } \\
\text { etapas }\end{array}$ & $\begin{array}{l}\text { Foco em engenharia e design de } \\
\text { produto, definição de um ciclo de } \\
\text { produto que vai desde as } \\
\text { necessidades, passa por testes de } \\
\text { aceitação e vai até a retirada do } \\
\text { mercado }\end{array}$ \\
\hline $\begin{array}{l}\text { ROZENFE } \\
\text { LD (1991) }\end{array}$ & $\begin{array}{l}\text { Planejamento estratégico e } \\
\text { de projeto }\end{array}$ & $\begin{array}{l}\text { Projetos informacional, conceitual e } \\
\text { detalhado } \\
\text { Preparação da produção } \\
\text { Lançamento }\end{array}$ & $\begin{array}{l}\text { Acompanhamento } \\
\text { do produto e do } \\
\text { processo } \\
\text { Descontinuidade }\end{array}$ & $\begin{array}{l}\text { Estrutura sequencial } \\
\text { com realimentação } \\
\text { de informações entre } \\
\text { as etapas }\end{array}$ & $\begin{array}{l}\text { Modelo bastante detalhado de } \\
\text { atividades, utilizando ferramentas e } \\
\text { métodos em diversas etapas do } \\
\text { processo de desenvolvimento de } \\
\text { produtos. } \\
\text { Contempla certificação de produto na } \\
\text { fase de preparação da produção do } \\
\text { produto. }\end{array}$ \\
\hline $\begin{array}{l}\text { KAMINSKI } \\
(2000)\end{array}$ & $\begin{array}{l}\text { Especificação de } \\
\text { necessidades } \\
\text { Estudo de viabilidade }\end{array}$ & $\begin{array}{l}\text { Projetos básico e executivo } \\
\text { Planejamento da produção e execução, } \\
\text { disponibilização ao cliente e consumo }\end{array}$ & $\begin{array}{l}\text { Planejamento do } \\
\text { abandono do } \\
\text { produto }\end{array}$ & $\begin{array}{l}\text { Estrutura em espiral } \\
\text { onde o fluxo de } \\
\text { informações entre } \\
\text { etapas ocorre em } \\
\text { ciclos }\end{array}$ & $\begin{array}{l}\text { Define o conceito de espiral de projeto, } \\
\text { contempla qualidade do produto desde } \\
\text { a fase de projeto, através de medidas } \\
\text { preventivas e corretivas }\end{array}$ \\
\hline $\begin{array}{l}\text { BAXTER } \\
(2011)\end{array}$ & $\begin{array}{l}\text { Identificação de uma } \\
\text { oportunidade } \\
\text { Pesquisa de marketing } \\
\text { Análise de concorrentes } \\
\text { Proposta do novo produto } \\
\text { Especificação da } \\
\text { oportunidade }\end{array}$ & Especificação do projeto & N/A & $\begin{array}{l}\text { Estrutura sequencial } \\
\text { com fluxo de } \\
\text { informação ente as } \\
\text { etapas }\end{array}$ & $\begin{array}{l}\text { Aborda o processo de inovação no } \\
\text { processo de desenvolvimento de } \\
\text { produtos, com metodologia de geração } \\
\text { e seleção de ideias, chamada de funil } \\
\text { de decisões }\end{array}$ \\
\hline
\end{tabular}


Quadro 1 - Quadro comparativo dos principais Modelos de Desenvolvimento de Produtos analisados neste trabalho

\begin{tabular}{|c|c|c|c|c|c|}
\hline Modelo & & vidade / Etapas de desenvolvimento & & $\begin{array}{l}\text { Estrutura e fluxo de } \\
\text { informacão }\end{array}$ & Principais características \\
\hline $\begin{array}{l}\text { SILVA } \\
(2012)\end{array}$ & $\begin{array}{l}\text { Esclarecimento das tarefas } \\
\text { Planejamento estratégico }\end{array}$ & $\begin{array}{l}\text { Projetos conceitual, preliminar e } \\
\text { detalhado } \\
\text { Processo de fabricação e manutenção } \\
\text { Protótipo } \\
\text { Validação do produto } \\
\text { Lançamento }\end{array}$ & $\begin{array}{l}\text { Acompanhamento } \\
\text { do produto e do } \\
\text { processo } \\
\text { Engenharia } \\
\text { reversa } \\
\text { Finalização do } \\
\text { suporte ao } \\
\text { produto }\end{array}$ & $\begin{array}{l}\text { Estrutura sequencial } \\
\text { em espiral com } \\
\text { realimentação de } \\
\text { informações entre as } \\
\text { etapas }\end{array}$ & $\begin{array}{l}\text { Foco em projeto de engenharia com } \\
\text { fases bem definidas e detalhadas. }\end{array}$ \\
\hline
\end{tabular}

Fontes: Os autores, adaptado de Asimow (1968), Kotler (1974), Back (1983), Rozenfeld (1991), Kaminski (2000), Baxter (2011) e Silva (2012) 
O modelo é composto por três macro-fases: pré-desenvolvimento, contemplando o esclarecimento das tarefas, geração e triagem das ideias e planejamento estratégico; desenvolvimento que promove as etapas de projeto informacional, projeto conceitual, projeto detalhado, preparação da produção e seu lançamento; pós desenvolvimento que acompanha o produto e o processo após sua comercialização e trata das medidas de descontinuação do produto no mercado.

É importante ressaltar que, na etapa de preparação da produção, o lote piloto do produto deverá ser submetido aos ensaios que irão confirmar sua compatibilidade dos requisitos estabelecidos pelas normativas da União Europeia e, caso não sejam aprovados, deverão voltar à fase de projeto informacional, tratando os requisitos não aprovados, justificando a importância de considerar todos os requisitos desde a fase de concepção do produto.

As sessões seguintes irão descrever detalhadamente cada etapa destacando quais as atividades relacionadas à certificação CE foram propostas.

Figura 2 - Modelo de Desenvolvimento de Produtos proposto

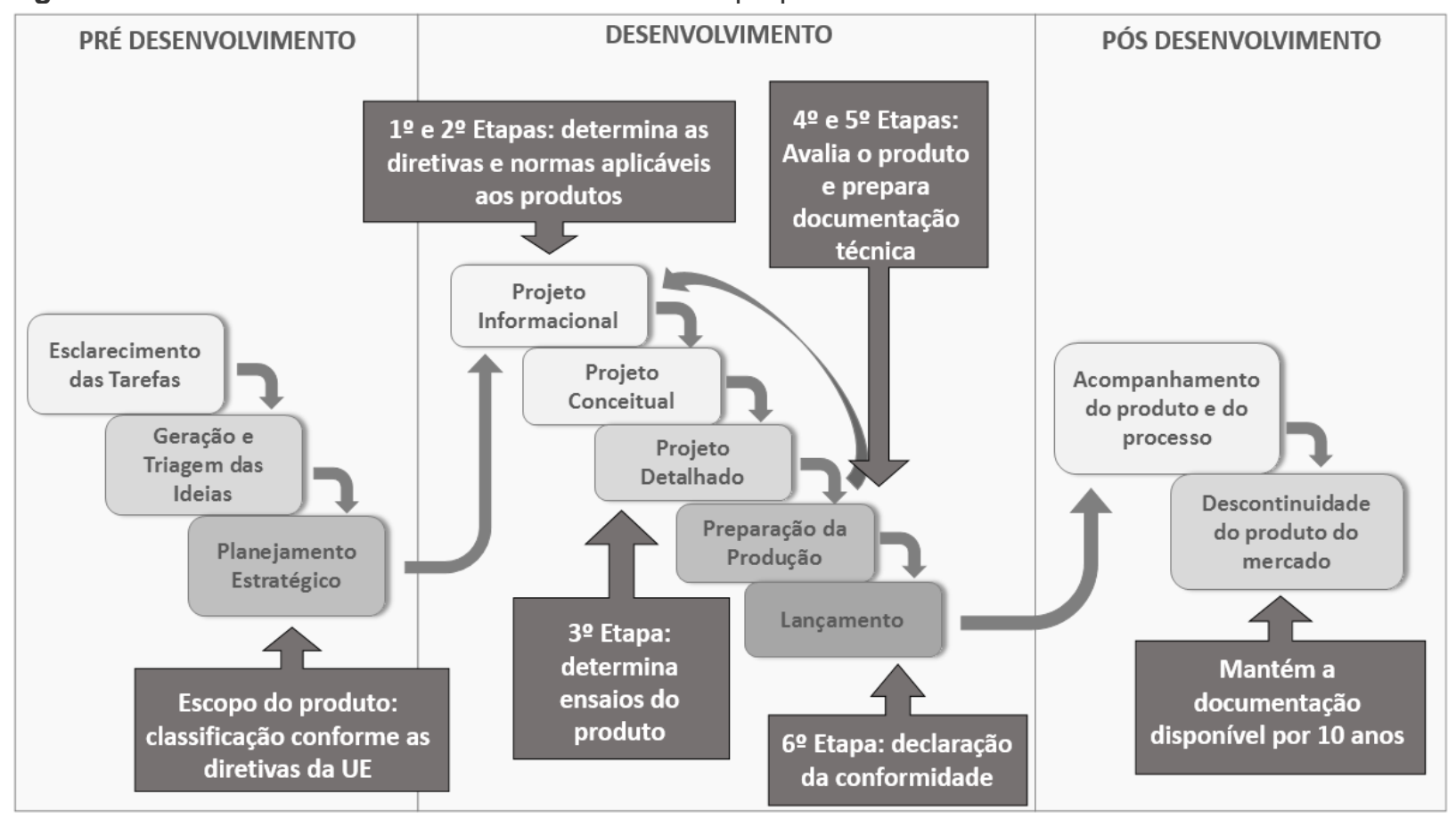

Fonte: Os autores

O Quadro 2 apresenta um resumo das atividades necessárias em cada fase de pré-desenvolvimento, desenvolvimento e pós desenvolvimento do modelo de desenvolvimento de produtos proposto. 
Quadro 2 - Fases e atividades do modelo de desenvolvimento de produtos proposto

\begin{tabular}{|c|c|c|}
\hline \multirow{3}{*}{ 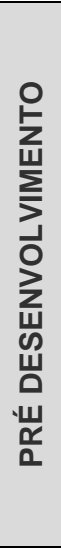 } & $\begin{array}{l}\text { Esclarecimento das } \\
\text { tarefas }\end{array}$ & $\begin{array}{l}\text { Identificação de necessidades de mercado. } \\
\text { Identificação de recursos disponíveis. } \\
\text { Contextualização da empresa e suas metas e objetivos. }\end{array}$ \\
\hline & $\begin{array}{l}\text { Geração e triagem } \\
\text { de ideias }\end{array}$ & $\begin{array}{l}\text { Formulação de ideias/soluções que relacionem as necessidades de mercado, o } \\
\text { contexto da empresa e os recursos disponíveis. } \\
\text { Apresentação das ideias a uma pequena amostra de consumidores. } \\
\text { Escolha das melhores soluções de acordo com a opinião dos consumidores. }\end{array}$ \\
\hline & $\begin{array}{l}\text { Planejamento } \\
\text { Estratégico }\end{array}$ & $\begin{array}{l}\text { Define um Plano Estratégico de Negócios - metas, recursos, prazos, atividades, } \\
\text { coleta de informações, tendências, competências, entre outros. } \\
\text { Identifica interessados no projeto. } \\
\text { Define o escopo do produto e do projeto: a partir do escopo o produto } \\
\text { poderá ser classificado conforme as diretivas da CE. } \\
\text { Define um cronograma de atividades e sequência. } \\
\text { Análise de riscos. } \\
\text { Estimativa de custos do projeto e análise da viabilidade econômica do projeto. }\end{array}$ \\
\hline \multirow{5}{*}{ 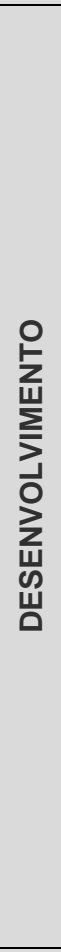 } & $\begin{array}{l}\text { Projeto } \\
\text { Informacional }\end{array}$ & $\begin{array}{l}\text { Detalha o ciclo de vida do produto, seus clientes, requisitos e especificações. } \\
\text { Executa a primeira e a segunda etapa da metodologia de certificação CE: } \\
\text { determina as diretivas e as normas harmonizadas aplicáveis aos produtos. } \\
\text { Monitora a viabilidade econômica do desenvolvimento. }\end{array}$ \\
\hline & Projeto Conceitual & $\begin{array}{l}\text { Modelagem funcional do produto. } \\
\text { Soluções para cada função do produto. } \\
\text { Define arquitetura, estética, ergonomia e gera alternativas. }\end{array}$ \\
\hline & Projeto Detalhado & $\begin{array}{l}\text { Planeja o processo de fabricação do produto: ciclo de vida, processo, materiais, } \\
\text { equipamentos, embalagem, fornecedores, ensaios funcionais. } \\
\text { Executa a terceira etapa da metodologia de certificação CE: determina os } \\
\text { ensaios que deverão ser realizados no produto. }\end{array}$ \\
\hline & $\begin{array}{l}\text { Preparação da } \\
\text { Produção }\end{array}$ & $\begin{array}{l}\text { Obtém recursos de fabricação. } \\
\text { Produção piloto. } \\
\text { Homologação do processo. } \\
\text { Otimização da produção. } \\
\text { Treinamento de pessoal para produção. } \\
\text { Executa a quarta e a quinta etapa da metodologia de certificação CE: avalia } \\
\text { o produto através da realização dos ensaios e prepara sua documentação } \\
\text { técnica, caso aprovado. Caso não seja aprovado, deverá retornar à etapa } \\
\text { de projeto informacional. }\end{array}$ \\
\hline & Lançamento & $\begin{array}{l}\text { Processos de venda, distribuição e atendimento ao cliente. } \\
\text { Suporte técnico. } \\
\text { Plano de fim de vida. } \\
\text { Executa a sexta etapa da metodologia de certificação CE: emite a } \\
\text { Declaração de Conformidade e confere marcação CE ao produto e } \\
\text { embalagem. }\end{array}$ \\
\hline \multirow{2}{*}{ 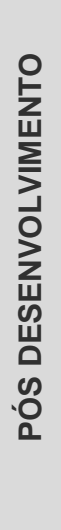 } & $\begin{array}{l}\text { Acompanhamento } \\
\text { do Produto e do } \\
\text { Processo }\end{array}$ & $\begin{array}{l}\text { Avalia satisfação do cliente. } \\
\text { Monitora o desempenho do produto. }\end{array}$ \\
\hline & $\begin{array}{l}\text { Descontinuidade do } \\
\text { Produto no Mercado }\end{array}$ & $\begin{array}{l}\text { Planeja a descontinuidade do produto, prepara o recebimento e finaliza o } \\
\text { suporte ao produto. } \\
\text { Avalia a possibilidade de utilização dos produtos retirados do mercado, ou parte } \\
\text { deles, na criação de novos produtos - gera recursos para primeira etapa de } \\
\text { desenvolvimento de um novo projeto. } \\
\text { Mantém a documentação da certificação CE disponível por } 10 \text { anos após a } \\
\text { descontinuidade do produto. }\end{array}$ \\
\hline
\end{tabular}

Fonte: Os autores 


\subsection{Esclarecimento das Tarefas}

O Esclarecimento das Tarefas é a primeira fase do pré-desenvolvimento, e tem como objetivo identificar possíveis necessidades de mercado, as quais poderão dar origem ao projeto de um novo produto. Nesta fase é importante definir o escopo do problema oriundo da necessidade de mercado, os recursos disponíveis para sua solução e as possíveis restrições que poderão limitar o projeto. Ainda nesta fase deve ser realizada uma contextualização da empresa no âmbito de suas metas e objetivos, afim de integrar a necessidade de mercado com seu know how para desenvolver um produto que venha a suprir tal necessidade.

\subsection{Geração e Triagem das Ideias}

A Geração e Triagem de Ideias consiste na formulação de soluções que relacionam as necessidades de mercado, o contexto da empresa e os recursos disponíveis para geração de alternativas viáveis possibilitando dar continuidade ao projeto. Essas alternativas são apresentadas a uma pequena amostra de consumidores, para que sejam avaliadas quanto a sua funcionalidade. A partir da opinião dos consumidores é escolhida a melhor alternativa, sobre a qual o projeto será consolidado.

\subsection{Planejamento Estratégico}

$\mathrm{Na}$ fase de Planejamento Estratégico é definido um plano estratégico de negócios que contempla as metas os recursos disponíveis, os prazos, as atividades a serem desenvolvidas, coleta de informações, tendências e competências. São identificados os interessados no projeto para determinar a participação dos integrantes e definir um cronograma de atividades e sequência. É realizada a análise de risco do projeto, que permite avaliar sua viabilidade. Nesta fase também é criado o escopo do produto, que define o que é, as principais funcionalidades e os possíveis materiais disponíveis para sua confecção. Essa etapa de desenvolvimento será entrada para a primeira etapa de certificação CE, uma vez que é necessário classificar o produto antes de enquadrá-lo nas diretivas da União Europeia. 


\subsection{Projeto Informacional}

O Projeto Informacional, primeira fase do desenvolvimento, irá especificar detalhes do ciclo de vida do produto, seus clientes, requisitos e especificações. Nesta fase deverá ser realizada a primeira etapa da certificação CE que determina as diretivas aplicáveis ao produto em desenvolvimento. Ao estabelecer os requisitos do produto, propõe-se que sejam, além de especificações alinhadas às necessidades de mercado e disponibilidades de recursos, considerações sobre as condições que aprovam o produto para certificação CE. Para que esses requisitos sejam especificados é necessário executar a segunda etapa da certificação CE, determinando os requisitos que o produto deverá atender quando for avaliado nas etapas seguintes. O produto que for projetado conforme esses requisitos terá maior chance de ser aprovados nas avaliações e receber a certificação CE, uma vez que já terá sido projetado em conformidade com tais requisitos. Finalmente, nesta fase também é realizado o monitoramento da viabilidade econômica do desenvolvimento do produto.

\subsection{Projeto Conceitual}

O Projeto Conceitual propõe a modelagem funcional do produto apontando soluções para cada uma de suas funcionalidades. Nesta fase são realizadas pesquisas sobre tendências, público-alvo, locais de comercialização, fornecedores, ciclo de vida do produto, resultando então, em uma lista com as configurações de oportunidade do produto. Também são definidos nesta fase a arquitetura, estética e ergonomia do produto. É interessante ressaltar que, ao definir o produto, devem ser considerados todos os requisitos e especificações apresentados na etapa anterior.

\subsection{Projeto Detalhado}

O Projeto Detalhado planeja o processo de fabricação do produto, incluindo tudo que será necessário para que esteja pronto para o mercado, tais como: ciclo de vida, processos de fabricação e montagem, materiais e equipamentos necessários, embalagem, fornecedores e planos de ensaios funcionais. Nesta etapa deve-se 
incluir a terceira etapa da certificação CE, determinando junto com processo produtivo quais são os ensaios que o produto deverá ser submetido para avaliar a conformidade com os requisitos estabelecidos nas normas da União Europeia.

\subsection{Preparação da Produção}

Durante a Preparação da Produção são levantados recursos para fabricação e é produzido um lote piloto. Juntamente com os recursos para produção devem ser considerados recursos para certificação, já que muitos ensaios podem necessitar de laboratórios terceirizados e transporte para homologação. A partir do lote piloto é possível executar a quarta etapa, avaliando o produto em laboratórios qualificados. Caso o produto não seja aprovado na avaliação, o processo de desenvolvimento de produtos deverá retornar à fase de projeto informacional, ajustando as especificações e repetindo as demais fases, até que seja aprovado. Ainda nesta fase é possível produzir a documentação técnica do produto, executando a quinta etapa da certificação CE.

Também nesta fase é realizada a homologação do processo produtivo que irá confirmar se o mesmo está adequado ao ritmo e necessidades da empresa e de mercado. A partir da homologação do processo é possível determinar práticas visando sua otimização, tais como melhorias em maquinários, treinamento dos colaboradores e avaliação de matéria prima.

\subsection{Lançamento}

Na fase de Lançamento do Produto, são realizadas atividades necessárias para comercialização e distribuição do produto, com o apoio das estratégias táticas e de marketing. Deverá ser conferida a Declaração de Conformidade e atribuída a marcação CE ao produto, na ocasião de seu lançamento, atestando sua conformidade com os requisitos estabelecidos pela União Europeia. Com isso é concluído a sexta e última etapa da metodologia de certificação. 


\subsection{Acompanhamento do produto e do processo}

No Pós-Desenvolvimento, a fase Acompanhamento do Produto e Processo, visa obter melhorias no produto através seu acompanhamento no mercado. A satisfação do cliente é avaliada constantemente e o desempenho do produto é monitorado para definir eventuais melhorias interessantes nas próximas revisões.

\subsection{Descontinuidade do Produto no Mercado}

A fase de Descontinuação do Produto no Mercado promove a engenharia reversa e finalização do suporte ao produto, que ocorrem quando não se realiza mais assistência técnica ou então as peças daquele produto já não são mais fabricadas, decorrente do declínio no seu ciclo de vida útil. Nesta fase são considerados fluxos de logística reversa para retirada do produto do mercado e é avaliada a possibilidade de aproveitamento integral ou parcial do produto no desenvolvimento de novos produtos.

Finalmente, quando houver a decisão de descontinuar o produto, deverá existir uma política na empresa para que toda a documentação técnica deste produto que confirme a Declaração de Conformidade com os requisitos da UE esteja disponível por pelo menos 10 anos após a sua última comercialização.

\section{CONCLUSÕES}

A revisão bibliográfica apresentada neste trabalho permite dizer que, embora existam muitas literaturas que apresentam modelos de desenvolvimento de projetos, cada uma delas é focada em uma metodologia e permitem melhoramentos que acrescentem atividades importantes.

A certificação de produtos segundo as normativas é considerada nas fases finais de alguns modelos. Este trabalho propôs acrescentar atividades que promovem a certificação do produto em relação à Conformidade Europeia desde as fases iniciais de desenvolvimento para aumentar as chances de aprovação do produto garantindo a Certificação CE e minimizar os custos da certificação. Desde da fase de concepção do produto, a partir da escolha das matérias-primas devem 
ser observadas as diretrizes da Certificação CE pois esta escolha inadequada pode inviabilizar a obtenção deste certificado.

A criação de um modelo unificado, que contempla as fases de diversos modelos propostos na literatura e acrescidos as atividades relativas a certificação CE confere ao trabalho um carácter inovativo e contribui para literatura pertinente ao processo de desenvolvimento de produtos e projetos.

Salienta-se que este modelo proposto precisa ser validado por meio da sua utilização em diferentes contextos a fim de identificar potenciais melhorias incluindo a simplificação de algumas atividades.

\section{REFERÊNCIAS}

ARCHER, L. B. The structure of design processes. London: Royal College of Art, 1968. ASIMOW, Morris. Introdução ao projeto de engenharia. Ed. Mestre Jou. São Paulo,1968. BACK, Nelson. Metodologia de projeto de produtos industriais. Rio de Janeiro. Ed. Guanabara Dois, 1983.

BAXTER, Mike. Projeto de produto: guia prático para o design de novos produtos. 3. ed. rev. São Paulo: Edgard Blücher LTDA. 2011.

BONFIM, G. A. Metodologia para desenvolvimento de projetos. João Pessoa: Editora Universitária - UFPB, 1995.

BONSIEPE, Gui; KELLNER,Petra; POESSNECKER, Holger. Metodologia experimental: desenho industrial. Brasília: CNPq/ Coordenação editorial. 1984.

BÜRDEK, Bernhard E. Design: história, teoria e prática do design de produtos. Tradução: Freddy Van Camp. 2 ed. São Paulo: Edgard Blücher LTDA. 2010.

CRAWFORD, C. M. New product management. Burr Ridge, IIL: Irwin, 1983.

EUROPA COMMISSION. Harmonised Standards. Disponível em $<$ http://ec.europa.eu/enterprise/policies/europeanstandards/harmonisedstandards/index_en.htm> Acesso em 09 de Abril de 2014.

JONES, C. J. Métodos de diseño. Barcelona: Gustavo Gili, 1976.

KAMINSKI, Paulo Carlos. Desenvolvendo produtos com planejamento, criatividade e qualidade. Rio de Janeiro: LTC, 2000.

KOTLER, Philip. Administração de Marketing: análise, planejamento, implementação e controle. Ed. Atlas S. A. São Paulo: 1974. 
LACERDA, Antonio Correa de. Globalização e investimento estrangeiro no Brasil. São Paulo. Saraiva, 2004.

LOBACH.Bernd. Design Industrial: bases para a configuração dos produtos industriais. Tradução: Freddy Van Camp. São Paulo: Edgar Blucher, 2001.

PAHL, G. et al. Projeto na engenharia: fundamentos do desenvolvimento eficaz de produtos, métodos e aplicações. São Paulo: Edgar Blücher, 2005.

PAHL, G., BEITZ, W. Konstruktionslehre. Berlim: Springer, 1977. http://dx.doi.org/10.1007/978-3-662-02288-7

PRASAD, B. Concurrent engineering fundamentals: integrated product development. Londres: Prentice-Hall, 1997. http://dx.doi.org/10.1177/1063293X9700500310

ROOZENBURG, N. F. M., EEKELS, J. Product desing: fundamentals and methods. 1996.

ROZENFELD, Henrique. et al. Gestão de desenvolvimento de produtos: uma referência para a melhoria do processo. São Paulo: Saraiva, 2006.

SILVA, Silvana. G. SANTOS, Adriana de Paula. L. Inovação no Processo de desenvolvimento de Produtos. Gesit, Curitiba. 2012.

SUH, N. P. The principles of design. New York: Oxford Press, 1988.

ULRICH, K.T.; EPPINGER, S.D. Product design and development. 2nd ed. New York: McGraw-Hill, 2004.

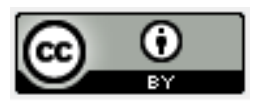

Artigo recebido em 07/12/2014 e aceito para publicação em 22/04/2015

DOI: http://dx.doi.org/ 10.14488/1676-1901.v15i3.1942 